\title{
Lancisi sign in a 69-year-old man with severe tricuspid regurgitation
}

\author{
Philipp Jud MD, Nicolas Verheyen MD
}

- Cite as: CMAJ 2018 January 8;190:E17. doi: 10.1503/cmaj.171297

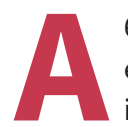

69-year-old man with severe tricuspid regurgitation was evaluated for tricuspid valve surgery. He reported increasing leg edema and shortness of breath at mild exertion, despite optimal pharmacologic therapy that included diuretic agents and an angiotensin-converting enzyme inhibitor. He did not have an implanted pacemaker. On physical examination, the patient had palpable and prominent systolic pulsations of both external jugular veins, known as $\mathrm{C}-\mathrm{V}$ waves or Lancisi sign (a video [Appendix 1] is available at www.cmaj.ca/lookup/suppl/ doi:10.1503/cmaj.171297/-/DC2). Electrocardiography showed atrial fibrillation (Appendix 2 is available at www.cmaj.ca/lookup/ suppl/doi:10.1503/cmaj.171297/-/DC1) and transthoracic echocardiography (Figure 1) confirmed severe tricuspid regurgitation.

The physiologic central venous waveform includes three peaks (A-, C- and V-waves) and two descents (X-and Y-descent). The A-wave results from atrial contraction in late diastole, followed by the $\mathrm{C}$-wave in early systole (from isovolumetric ventricular contraction against the closed tricuspid valve) and the $\mathrm{X}$-descent in midsystole (from atrial relaxation). The $\mathrm{V}$-wave occurs during late systole (from atrial filling), whereas Y-descent occurs in early diastole (from passive ventricular filling). In substantial tricuspid regurgitation, systolic blood flow into the right atrium results in a merged $\mathrm{C}-\mathrm{V}$ wave because of a loss of the X-descent (Lancisi sign).

After tricuspid valve repair using an annuloplasty ring, the patient's symptoms resolved completely, and the C-V wave pattern of pulsations in his external jugular veins resolved (a video [Appendix 3] is available at www.cmaj.ca/lookup/suppl/doi:10.1503/ cmaj.171297/-/DC2).

\footnotetext{
Competing interests: None declared.

This article has been peer reviewed.

The authors have obtained patient consent.

Affiliations: Divisions of Angiology (Jud) and Cardiology (Verheyen), Department of Internal Medicine, Medical University of Graz, Graz, Austria
}

Correspondence to: Philipp Jud, philipp.jud@medunigraz.at

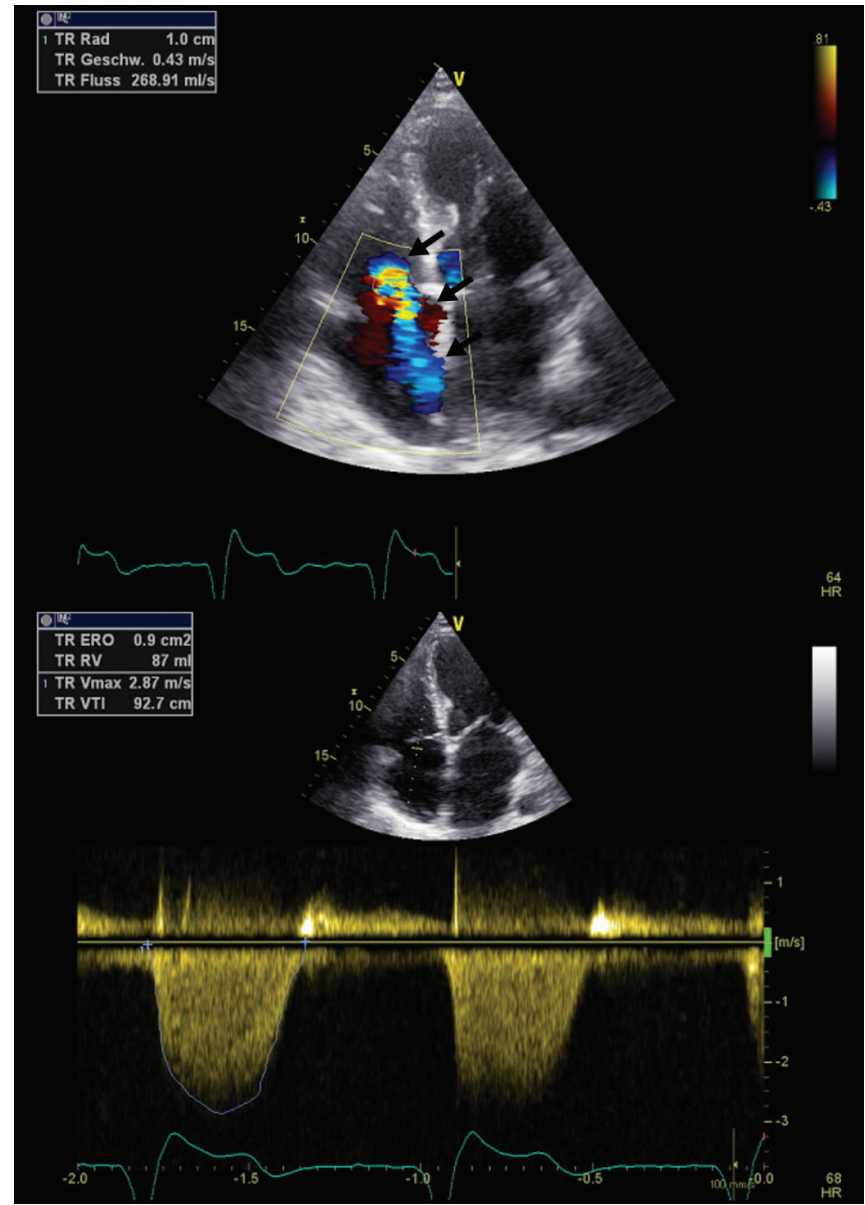

Figure 1: Transthoracic echocardiograph in apical four-chamber view in a 69-year-old man showing severe tricuspid regurgitation with an effective regurgitant orifice area of $0.9 \mathrm{~cm}^{2}$. Black arrows point towards the central jet.

Please see the following videos online:

Lancisi sign in both external jugular veins

Normalized venous filling of both external jugular veins without Lancisi sign after tricuspid repair

www.cmaj.ca/lookup/suppl/doi:10.1503/cmaj.170361/-/DC2 